\title{
Sexual violence victimisation among university students in Italy: a gendered intersectional quantitative approach
}

\author{
Livia Elisa Ortensi ${ }^{1^{*}}$ (D) and Patrizia Farina ${ }^{2}$
}

\author{
* Correspondence: livia.ortensi@ \\ unibo.it \\ ${ }^{1}$ Alma Mater Studiorum, University \\ of Bologna, Via delle Belle Arti 41, \\ 40126 Bologna, Italy \\ Full list of author information is \\ available at the end of the article
}

\begin{abstract}
There is rising attention in Italy and Europe to the occurrence, consequences, and factors related to sexual violence. The focus on women as the primary victims of sexual violence has, however, left data collection and research on young men and sexual minorities in the background. Moreover, young people's experiences of sexual abuse in the context of their relationships with peers are hardly recognised as a policy concern. The ultimate aim of this paper is to disentangle intersectionalities between gender, migration background, sexual orientation, and sexual experience in shaping the risk of experiencing sexual violence among university students in Italy. We use data from the Sexual and Emotional LiFe of Youths (SELFY) survey carried out in Italy in 2017. Our data confirm that women and foreign-born students are at higher risk of sexual violence. Our data also support previous evidence that bisexual women are at a higher risk of sexual violence victimisation compared with peer students with other sexual orientations. Previous same-sex sexual experience is more relevant than sexual orientation in shaping the risk. The effect is gendered: the risk of sexual violence is lower for women with previous same-sex sexual experience compared with their male peers. The intersection between gender, sexual orientation, and same-sex sexual experience generate specific high-risk profiles whose needs should be targeted by support services.
\end{abstract}

Keywords: Sexual violence, Gender-based violence, University students, Sexual minorities, Italy

\section{Introduction}

There is rising attention in Italy and Europe to the occurrence, consequences, and factors related to sexual violence. Sexual violence is defined as any sexual activity that occurs without explicit consent from the other person (WHO - World Health Organization, 2002). Sexual violence victimisation (SVV) is a crucial issue at the national and global level, and severe human rights, health, and public policy concern (WHO, 2012). Victims of sexual violence endure extensive adverse health and psychological impacts along with negative education outcomes, including dropout (Campbell, 2002; Buller, Devries, Howard, \& Bacchus, 2014; Reuter, Newcomb, Whitton, \& Mustanski, 2017; WHO, 2012). Research in different settings, including Italy, has shown

(c) The Author(s). 2020 Open Access This article is licensed under a Creative Commons Attribution 4.0 International License, which permits use, sharing, adaptation, distribution and reproduction in any medium or format, as long as you give appropriate credit to the original author(s) and the source, provide a link to the Creative Commons licence, and indicate if changes were made. The images or other third party material in this article are included in the article's Creative Commons licence, unless indicated otherwise in a credit line to the material. If material is not included in the article's Creative Commons licence and your intended use is not permitted by statutory regulation or exceeds the permitted use, you will need to obtain permission directly from the copyright holder. To view a copy of this licence, visit http://creativecommons.org/licenses/by/4.0/. 
that SVV is strongly age-dependent, with young adults and teenagers being more at risk (Sinozich \& Langton, 2014; List, 2013; Ngo, Veliz, Kusunoki, Stein, \& Boyd, 2018; Martin-Storey et al., 2018; ISTAT, 2016; Kubicek, 2018). For this reason, a relevant stream in SVV-related literature focuses on university students (Fedina, Holmes, \& Backes, 2016; Wiersma-Mosley \& Jozkowski, 2019). Worldwide research shows that educational institutions such as universities and schools are the most common places in which sexual coercion and harassment are experienced (Henry, 2019; WHO, 2012; Debauche et al., 2017; Lebugle, Dupuis, et al., 2018). Nonetheless, the lack of comprehensive, high-quality data is recurrent in exploring young adults' experiences of sexual abuse in the context of their relationships with peers (Romito, Beltramini, \& EscribàAgüir, 2013; STIR- Safeguarding Teenage Intimate Relationships, 2016).

Some crucial issues raised by studies focusing on SVV among the overall population are entirely relevant to research on university students. Data collection on men and sexual minorities (lesbian, gay, bisexual, or transsexual couples; LGBT) is limited. Men have only recently been recognised as targets of sexual aggression or coercion (Krahè, Scheinberger-Olwig, \& Bieneck, 2003; Lehrer, Lehrer, \& Koss, 2013; Elliot et al., 2004). At the same time, SVV is a crucial issue also among LGBT couples (Walters, Chen, \& Breiding, 2013): evidence suggests that SVV among LGBT couples is comparable with or higher than in heterosexual populations (Badenes-Ribera, Frias-Navarro, BonillaCampos, Pons-Salvador, \& Monterde-i-Bort, 2015; Langenderfer-Magruder, Whitfield, Walls, Kattari, \& Ramos, 2016; Lockhart, White, Causby, \& Isaac, 1994; Reuter et al., 2017). Moreover, in the context of growing ethnic complexity, the immigrant status arises as a factor potentially driving gender-based violence vulnerability. However, the role of the migration background is currently poorly understood: studies correlating the migrant background and the risk of SVV have shown mixed and community-specific results (Offenhauer \& Buchalter, 2011; Silverman, Decker, \& Raj, 2007).

In the Italian context, most research focuses on adult men's violence against women. In contrast, evidence on men as victims of sexual violence is mainly found in studies on same-sex relationships or anecdotally described in reports from shelter centres (Maschile Plurale, 2020). Moreover, most papers follow a psychological approach (Baldry \& Winkel, 2004; Prino, Longobardi, \& Settanni, 2018), and none of the studies focuses on the intersectionality of crucial aspects like gender, sexual orientation, or migrant status. An analysis of how the interconnected nature of such social categorisations overlaps creating higher or lower vulnerability to SVV is currently missing in the Italian setting. Finally, evidence related to SVV among university students and youth is currently limited in Italy and needs to be studied further (Rollè, Giardina, Caldarera, Gerino, \& Brustia, 2018) to inform and support policymaking.

Given this background, we focus on university students providing evidence on the self-declared experience of SVV, using data collected in Italy in 2017 from approximately 7800 respondents in the framework of the SELFY project (Dalla Zuanna, Caltabiano, Minello, \& Vignoli, 2019). The aim of our study is manifold. First, we update evidence on SVV among students enrolled in Italian universities using a large nationallevel dataset. Second, our work adds upon much-requested research on male victims and sexual minorities in the Italian context. Third, we extend the discussion to foreignborn students. Given the relatively recent history of Italy as a country of immigration and its limited relevance as a magnet for incoming university students from abroad, 
research including both natives and foreign-born students is scarce in the Italian setting. Most importantly, we analyse intersectionalities between these factors and their association with self-reported SVV.

\section{Theoretical background}

\section{Sexual violence victimisation among students}

The first seminal quantitative study on SVV among university students in the USA was carried out by Koss and Oros in Koss \& Oros, 1982. This study opened the way to a relevant number of studies underlining the worldwide importance of the topic, its drivers, and the impact on health (Fisher, Cullen, \& Turner, 2000; Krebs, Lindquist, Warner, Fisher, \& Martin, 2007; Lehrer, Lehrer, \& Koss, 2012). Recent data collected in 2019 by the Association of American Universities (2020) suggest that sexual violence is still pervasive: the overall rate of nonconsensual sexual contact after students' enrollment was $13.0 \%$. SVV among university and high school students is a relevant issue also outside the USA. Research, especially in the context of dating violence, shows that university students are highly vulnerable to SVV because so many are involved in romantic relationships during these formable years (Gover, Kaukinen, \& Fox, 2008). Ages 18-25 occupy a distinct developmental phase called "emerging adulthood", a period characterised by growing independence, exploration, and experimentation in many aspects of life, including peer and romantic relationships. Because demographic and societal changes have increasingly delayed marriage and parenthood, it is no longer normative for the late teens and early twenties to be a time of entering and settling into long-term adult roles. It is the period of life that offers the most opportunity for identity explorations, and the phase when explorations in love become more intimate and profound (Arnett, 2000).

Research shows that being a woman, having many sexual partners, younger age at first intercourse, and dating less familiar men increase women's risk of sexual victimisation and revictimisation (Harned, 2002; Lebugle et al., 2018; Lehrer et al., 2013). Poor functioning and cohesion of the family of origin, substance use, and dating situations involving alcohol and drug use are also thought to increase the likelihood of SVV (Potter, 2016; Vézina \& Hérbert, 2007). Mixed findings in earlier research on the role of socioeconomic status suggest that the current understanding of its role as a risk factor for SVV during young adulthood is limited (Hines, 2007). Recent studies indicate that socioeconomic status might have a mediation role, usually losing significance after adding variables accounting for previous experience of or witnessing of violence in the childhood environment (Lehrer et al., 2013), the latter being a strong predictor of SVV (Gover et al., 2008).

Another crucial point is related to age at the first sexual experience. It has been observed that the onset of sexual activity is occurring earlier than in the past (Lloyd, 2007). The extensive research on early sexual debut suggests a strong relationship with SVV by showing a very blurred distinction between coerced sex and early first sexual intercourse or sexual experiences (Lee, Yuen Loke, Hung, et al, 2018). Recent research carried out in the USA on a broad sample of high school students including sexual minorities confirms the relationship between early sexual debut and SVV but finds no differences according to the students' sexual orientation (Lowry, Dunville, Robin, \& Kann, 2017). 
The literature has paid particular attention to gender, immigrant background, and sexual orientation that are the critical points of the present study.

As we stressed, female university students, and women in general, are far more exposed to SVV compared with male peers (WHO, 2012; Debauche et al., 2017; ISTAT, 2015; Lebugle et al., 2018). Recent data collected in several American universities suggest that the incidence of SVV is four times higher among women compared with men (Association of American Universities, 2020). However, there is consensus on the fact that SVV among male university students, and men and boys in general, is severely underestimated because victims are extremely unlikely to report an assault to the authorities or seek help (WHO, 2012; Choudhary, Coben, \& Bossarte, 2008; Sable, Danis, Mauzy, \& Gallagher, 2006). Larimer, Lydum, Anderson, and Turner (1999) found, during the 12 months preceding their study, an overall incidence rate of nonconsensual sexual experiences of $20.7 \%$ among a sample of university students. More recent research has substantiated the occurrence of the phenomenon of male SVV in different countries (Association of American Universities, 2020; Depraetere, Vandeviver, \& Vander, 2018; Hines, 2007; Krahè et al., 2003; Lebugle et al., 2018; Lehrer et al., 2013; Peterson, Voller, Polusny, \& Murdoch, 2011).

While gender is indeed relevant, the role of the immigrant background among high school and university students seems particularly complex to understand. Results from studies mostly carried out in the North American context are mixed and inconclusive. Evidence of higher risk of SVV is usually not consistent across age or racial/ethnic groups suggesting the existence of intricate patterns of risk and protective factors, and ethnic disparities (Decker, Raj, \& Silverman, 2007; Porter \& McQuiller, 2011; Silverman et al., 2007; Vézina \& Hérbert, 2007).

Finally, higher occurrence of SVV among LGBT university students and young adults compared with their heterosexual peers is a recurrent finding (Griner et al., 2020; Edwards \& Sylaska, 2013; Ford \& Soto-Marquez, 2016; Edwards et al., 2015a, b; Association of American Universities, 2020). In the case of LGBT young adults, assaults are also driven by the social stigma associated with the perception of sexual orientation and gender identity (Blondeel et al., 2018). Research has covered the topic of intimate partner violence among sexual minorities (Whitfield, Coulter, Langenderfer-Magruder, \& Jacobson, 2018). The social-ecological approach (Dardis, Dixon, Edwards, \& Turchik, 2015), the disempowerment theory (Edwards \& Sylaska, 2013), and the lack of original LGBT sexual scripts (Gagnon \& Simon, 1973) are frequent explanations for SVV in the framework of LGBT romantic relationships. As observed by Kubicek (2018), the literature on intersectionality has contributed a great deal to the understanding of how different dimensions like gender, sexual identity, and age interact or reinforce each other. The processes of racialisation and sexual identityrelated discrimination intersect disrupting the idea of women and men as homogenous collectives (Anthias, 2012). Seen through the lens of SVV, this implies that combinations of social categorisations might result in risk profiles higher or lower than the mere combination of risks related to each group ${ }^{1}$. Intersectionality is particularly relevant in explaining the recurrent finding that bisexual individuals are at higher risk of all forms of intimate partner violence than any other sexual-orientation group (Walters et al., 2013; Messinger, 2011;

\footnotetext{
${ }^{1}$ This point is operationalised in our study by testing and adding interactions to the baseline model 1 , as explained in the "Method" section.
} 
Whitfield et al., 2018). According to Messinger (2011), the victimisation of bisexual individuals may be perpetrated for different reasons by both same-sex and opposite-sex partners. Specifically, same-sex partners may attempt to regain power by being abusive toward their bisexual partner as a result of minority stress. In contrast, opposite-sex partners may not be able to relate to their bisexual partner's sexual orientation (Whitfield et al., 2018).

\section{The Italian context}

According to the latest data released by the Italian National Institute of Statistics (ISTA T) based on a national survey carried out in 2014, $21.0 \%$ of Italian women have experienced a form of sexual violence in their life (1.2 million), and 5.4\% experienced rape or attempted rape. Consistently to the international literature, the risk of SVV among Italian women is strongly age-dependent, resulting in the highest risks for teenagers and young adults. Students are especially at risk of sexual violence from a nonpartner offender. Moreover, foreign women have a lower incidence of SVV (16.2\%) but are more likely to experience rape or attempted rape (7.7\%) (ISTAT, 2015).

Data on sexual violence against men and sexual minorities are scarce in the Italian context, and the few existent studies have several methodological limitations and rely on small or convenience samples (Arcilesbica, 2011; Pelullo, Di Giuseppe, \& Angelillo, 2013; STIR- Safeguarding Teenage Intimate Relationships, 2016). Research on young students is also limited. A study carried out on intimate partner violence in 2007 on a sample of 726 high school students in the Italian region of Friuli Venezia-Giulia found a lifetime prevalence of SVV of $7.9 \%$ and $14.4 \%$ among boys and girls respectively (Romito et al., 2013). A study carried out in 2001 on 502 students enrolled in the Italian university of Trieste found that $10.5 \%$ of men and $19.9 \%$ of women reported lifetime experience of sexual violence (Romito \& Grassi, 2007).

Scarce evidence exists in the Italian context about SVV among foreign university students, which are a well-selected part of the first-generation young migrant population. More evidence exists for violence in selected settings like Latino gangs (Bugli e Conte, 2010) or sexual behaviours among young people with migrant backgrounds (Marmocchi, 2012).

Given this framework, and relating to the Italian context, we aim to answer the following research questions:

(RQ1) What is the occurrence of self-reported sexual violence among university students?

(RQ2) Is there a difference between the incidences of self-reported sexual violence among sexual minorities university students compared with their heterosexual peers? (RQ3) Do sexual experience, gender, and migration background interact with sexual minority status in the determination of the risk of SVV?

\section{Data and methods}

Data

To carry out the present research, we relied on data collected in 2017 in the framework of the SELFY (Sexual and Emotional LiFe of Youths) project. SELFY is a study carried out by the Universities of Padua, Messina, and Florence, as the second edition of the 
Italian Student Sexuality (ISS) survey initially carried out in 2001. The study aims at investigating the emotional life of university students through questions about their first emotionally significant relationships and sexual experiences. Respondents completed anonymous self-administered questionnaires, approved by ethical boards and introduced by a researcher during regular class hours. This investigation has involved nearly the entire population of economics and statistics undergraduate students taking courses at Italian public universities. The final sample consists of 7843 questionnaires collected at 23 universities (SELFY, 2019). Data were poststratified at the macroregion level to obtain representative results at the national level of the population of economics and statistics undergraduate students. Only $3.1 \%$ of the questionnaires initially collected were eliminated because they did not meet the quality requirement. This final database appears to be sufficiently reliable to conduct sophisticated statistical analyses (Dalla Zuanna et al., 2019). We should point out that the design of the study is crosssectional, so it is not possible to test the directionality or causality of the relations between independent and dependent variables. Despite some limitations due to the selectivity of the target population, the SELFY survey overcomes most limitations of studies carried out in the field of SVV, whose quality of data is often relatively low due to the use of small and non-randomised samples (Blondeel et al., 2018).

\section{Definitions}

To carry out the present study according to the information collected in the SELFY survey, the definitions of sexual violence, sexual minorities, and foreign-born individuals are relevant. It is worth underlining that the SELFY survey was not specifically designed to study violence, sexual minorities, or foreign-born populations. It has, therefore, several limitations that will be discussed.

\section{The definition of sexual violence}

To study the occurrence of sexual violence, we relied on the only available question formulated as follows: "Have you ever been forced into sexual experiences (not necessarily full sex) against your will?" The possible answers were "No; Yes, once; Yes, more than once." As only a small fraction of the sample responded, "Yes, more than once," we jointly analysed positive answers.

This definition of violence is limited to sexual coercion experience and therefore does not cover other relevant forms of violence like stalking or psychological, verbal, and physical violence. Moreover, as no examples were given to the respondents, the definition of "sexual experiences against one's will" is left to the subjective perception of the respondents that could lead to distortions. As in all surveys on violence, the selfdeclared experience of SVV does not account for all youths who actually experienced sexual coercion but only those who can recognise a degree of pressure in their experiences and are willing to declare it. We are fully aware that researching violence through multiple items aimed at disclosing different types of sexual violence, along with the use of behavioural and objective indicators, is preferable. Another limitation arises from the fact that no information is available about the age at the first experience of sexual

\footnotetext{
${ }^{2}$ The original formulation is "Sei mai stato costretto (stata costretta) ad avere esperienze sessuali - non necessariamente rapporti completi - contro la tua volontà?".
} 
violence. Even if the question is placed in a section dedicated to friendship and first romantic experiences, we cannot a priori exclude the possibility that the respondent recalled experiences related to his or her childhood. Drivers of violence during childhood are different from drivers of violence experienced by peers. Finally, information on the perpetrator is also missing.

\section{The definition of sexual minorities}

To define sexual minorities, we relied both on the self-declared sexual orientation (heterosexual, homosexual, bisexual) and same-sex sexual experiences (previous sexual experience with a person of the same sex: yes, no). This choice was driven by the assumption that the risk of experiencing violence could be related more to sexual experience than to sexual identity. Moreover, our data show that experience is not necessarily consistent with sexual orientation (Table 1).

As a limitation, students filling the questionnaire could not answer "unsure" when asked for their sexual orientation. As some students did not answer the question, we decided to recode these nonrespondents into the category "Does not declare sexual orientation" that appears in Table 1. Other limitations are related to the fact that it was also not possible for students to answer "transsexual or intersexual" as their gender and that the self-declared sexual orientation is expressed in categorial terms rather than expressed along a continuum. In fact, sexual orientation is considered to be fluid and can also change over time (Beckstead, 2012). We cannot a priori exclude that SVV could affect sexual orientation. On the positive side, several panel surveys have shown that the change of sexual orientation is rare, especially the shift from heterosexual to homosexual or bisexual identity/orientation. The transition between bisexuality and homosexuality is more frequent but still very limited (Gill \& Tutty, 1998; Mock \& Eibach, 2012).

\section{The definition of the population with a foreign background}

The survey collected information about the students' place of birth, allowing the possibility to indicate "foreign state" when relevant. For this reason, it is not possible to distinguish second-generation migrants (i.e. Italian-born children of one or both foreignborn parents) from natives. At the same time, it is not possible to distinguish a foreignborn student with a foreign background from a foreign-born student with an Italian background. Finally, no indication of the country of birth was collected.

Table 1 Percentage of students who declare previous same-sex sexual experience by gender and sexual orientation

\begin{tabular}{llllll}
\hline $\begin{array}{l}\text { Previous same-sex sexual } \\
\text { experience }\end{array}$ & Homosexual & Bisexual & Heterosexual & $\begin{array}{l}\text { Does not declare sexual } \\
\text { orientation }\end{array}$ & Total \\
\hline Total & 84.7 & 78.1 & 8.5 & 7.2 & 10.9 \\
Males & 91.1 & 64.6 & 5 & 8.2 & 7.2 \\
Females & 73.0 & 86.2 & 12.3 & 6.2 & 14.9 \\
$\mathrm{~N}$ & 84 & 176 & 7465 & 118 & 7,843 \\
\hline Source: SELFY Survey, 2017 & & & & &
\end{tabular}




\section{Methods}

Given the sensible and intrusive topic under study, we first aimed at applying a model correcting for nonresponse. We, therefore, tested a probit model with sample selection on responses to the question on the experience of violence. The likelihood ratio test of independent equations was, however, not significant. For this reason and considering the tiny fraction of nonrespondents to the question about previous experience of violence (1\%), we dropped them from the analysis and fit a set of logistic regression models.

We run preliminary analyses to detect possible multicollinearity of regressors. No variable displayed signs of serious multicollinearity. The mean value of variance inflation factors (VIF) was equal to 1.16, and values higher than 1.2 were only found for the two variables related to the parents' year of birth $^{3}$ (3.90 and 3.91).

We run a stepwise analysis to disentangle the relationship between gender, place of birth, sexual orientation, and sexual experience with someone of the same sex. We first fit model 1 without interactions. Then we introduced an interaction between sexual experience with someone of the same sex and gender in model 2. Finally, model 3 also contains the interaction between gender and sexual orientation. As interactions with the place of birth were not significant, we dropped them from the final model formulation. While we cannot exclude that the place of birth intersects with gender, same-sex sexual experience, or sexual orientation in enhancing or reducing the risk of SVV, the number of foreign-born individuals in the sample is not wide enough to provide statistical significance. By gradually introducing interactions, we improved the data fit as shown by Akaike information criterion (AIC) and McFadden's $R$ squared values in Table 4 and accounted for intersectionalities among key variables.

To better substantiate results, we report the predicted probabilities of experiencing SVV according to gender, place of birth, sexual orientation, and previous sexual experience with someone of the same sex, keeping all other variables at the mean (Williams, 2012).

\section{Measures}

The dependent variable is previous sexual experiences (not necessarily full sex) against the respondent's will (yes; no).

Independent variables are:

- Gender: female; male (reference)

- Year of birth: (in single years)

- Place of birth: Italy (reference); foreign state

- Self-declared sexual identity: Heterosexual (reference); Homosexual; Bisexual; Does not answer

- Previous sexual experience with a person of the same sex: yes, no (reference)

Control variables aim to account for the aspects discussed in the theoretical background that, although not the primary focus of our paper, are relevant to the literature: the parents' socioeconomic status and students' exposure to previous sexual experiences.

${ }^{3} \mathrm{~A}$ VIF value higher than 10 is most commonly regarded as a sign of severe or serious multicollinearity (O’brien, 2007). 
Table 2 Sample description according to selected characteristics, SELFY survey 2017

\begin{tabular}{lllll}
\hline Selected characteristics & Total sample & N & Victims of SVV & N \\
\hline \% female & 48.16 & 3777 & 68.76 & 250 \\
Mean age & 21 & 7843 & 21 & 339 \\
\% foreign born & 5.79 & 454 & 12.75 & 46 \\
\% graduated among fathers & 21.91 & 1759 & 20.54 & 74 \\
\% graduated among mothers & 22.84 & 1773 & 21.21 & 77 \\
\% homosexual & 1.07 & 84 & 1.58 & 6 \\
\% bisexual & 2.24 & 176 & 9.43 & 34 \\
\% heterosexual & 95.18 & 7465 & 86.91 & 316 \\
\% does not declare sexual orientation & 1.51 & 118 & 2.07 & 8 \\
\% with a previous same-sex sexual experience & 10.7 & 839 & 29.75 & 108 \\
\% age at first sexual experience 10-13 years & 13.31 & 1044 & 18.16 & 66 \\
\% age at first sexual experience 14-16years & 51.51 & 4040 & 62.31 & 227 \\
\% first sex before 15 years & 8.16 & 640 & 20.44 & 74 \\
\hline
\end{tabular}

Source: SELFY Survey, 2017

Control variables are:

- Father's education: no title to junior high school (reference); high school; university

- Mother's education: no title to junior high school (reference); high school; university

- Father's job: manager, professional, civil servant, etc. (reference); craftsman; clerk, teacher; blue-collar

- Mother's job: manager, professional, civil servant, etc. (reference); craftswoman; clerk, teacher; blue-collar

- Father's year of birth (in single years)

- Mother's year of birth (in single years)

- Age at first sexual experiences (not full sex): not happened yet (reference); 10-13 years; $14-16$ years; 17 and over; does not declare

- Age at first intercourse: not happened yet (reference); before 15 years; 15-18; 19 and over

\section{Results}

According to our data, $4.7 \%$ of economics and statistics undergraduate students attending lessons in Italian public universities experienced SVV in the form of sexual coercion in their life (RQ1). This proportion is higher among women (6.7\%) compared with their male peers (2.8\%). Experience of violence is more than twice as high among foreign-born students (10.5\%) than among students born in Italy (4.3\%). If we consider the self-declared sexual orientation, $6.9 \%$ of homosexual students and $19.5 \%$ bisexual students report at least an episode of SVV. The proportion is higher compared with their heterosexual peers (4.3\%). Finally, the experience of SVV is $12.9 \%$ among students who declare a previous same-sex sexual experience compared with an observed $3.7 \%$ among other students ${ }^{4}$ (RQ2).

Table 2 shows the characteristics of respondents in the total sample and the subsample of victims of sexual violence. Consistently with previous evidence, women,

${ }^{4}$ The Fisher exact test is significant $(p<0.001)$ for tables comparing SVV respectively by gender, place of birth, sexual orientation, and previous homosexual experience. 
Table 3 Proportion of students reporting SW by gender and sexual orientation (a-b), place of birth and sexual orientation $(c-d)$, and place of birth, gender, and sexual orientation (e-f)

\begin{tabular}{|c|c|c|c|c|c|c|c|c|c|}
\hline & \multirow{2}{*}{$\begin{array}{l}\text { Males } \\
\text { (a) }\end{array}$} & \multirow{2}{*}{$\begin{array}{l}\text { Females } \\
\text { (b) }\end{array}$} & \multirow{2}{*}{$\begin{array}{l}\text { Natives } \\
\text { (c) }\end{array}$} & \multirow{2}{*}{$\begin{array}{l}\text { Foreign- } \\
\text { born } \\
\text { (d) }\end{array}$} & \multicolumn{2}{|c|}{ Foreign-born (e) } & \multicolumn{2}{|c|}{ Natives (f) } & \multirow[t]{2}{*}{ Total } \\
\hline & & & & & Males & Females & Males & Females & \\
\hline Homosexual & 8.3 & 4.3 & 7.3 & 0 & 0 & 0 & 9 & 4.5 & 6.9 \\
\hline Bisexual & 5.3 & 28.3 & 20.2 & 9.9 & 12.4 & 8.1 & 4.7 & 29.7 & 19.5 \\
\hline Heterosexual & 2.6 & 6.0 & 3.9 & 10.3 & 10 & 10.5 & 2.3 & 5.7 & 4.3 \\
\hline DK & 10.5 & 10 & 7.7 & 23.2 & 43.5 & 13.7 & 6.7 & 9 & 10.3 \\
\hline Total & 2.8 & 6.7 & 4.3 & 10.5 & 10.6 & 10.5 & 2.5 & 6.4 & 4.7 \\
\hline N & 4066 & 3777 & 7389 & 454 & 191 & 263 & 3875 & 3514 & 7843 \\
\hline Fisher's exact test & 0.027 & 0.000 & 0.000 & 0.226 & 0.160 & 0.435 & 0.083 & 0.000 & \\
\hline
\end{tabular}

Source: SELFY Survey, 2017

Note: Data whose $p$-value is below 0.05 are italicised

foreign-born, sexual minorities are overrepresented among victims of sexual violence. Students who had sexual experiences and full sex at an early age are also overrepresented among victims of sexual violence.

SVV varies according to the intersections between gender, sexual identities, and place of birth. Descriptive statistics show that the proportion of SVV reported is exceptionally high among native bisexual women (29.7\%). It is also high among homosexual males (8.3\%) and among men who do not disclose their sexual orientation (10.5\%; Table 3).

Results from the logistic regression models show that, controlling for all other variables included in the model, female university students have a significantly higher risk of experiencing SVV compared to male peers. Foreign-born students also have twice the risk of experiencing SVV compared to Italian-born peers ${ }^{5}$.

To disentangle intersectionality in the relationship between gender, declared sexual orientation, and previous sexual experience with someone of the same sex, we introduced two interactions in models 2 and 3 following a stepwise process that improved the models' fit (Table 4). Model 1 shows that bisexual students have a higher risk of SVV compared with heterosexual students. The model also indicates that students not declaring their orientation have a higher risk of experiencing SVV compared with their peers who reported being heterosexual.

Previous sexual experience with someone of the same sex is also a risk factor for SVV. However, we observe that the effect of previous same-sex sexual experience is differentiated by gender when we insert the interaction in model 2. The risk of experiencing SVV is higher for men with previous sexual experience with someone of the same sex than for women ${ }^{6}$.

Finally, once we include the interaction between gender and sexual orientation in model 3, we see that no significant difference in the risk of SVV according to sexual orientation exists among men. Among women, though, we observe a higher risk of SVV among bisexuals compared to heterosexual women.

\footnotetext{
${ }^{5}$ Control variables for parents' education and job position display the expected direction. The model shows a protective effect of the father's higher job position (a proxy for the socioeconomic status of the family) and a slight protective effect of mother's higher education.

${ }^{6}$ Control variables show that the role of sexual experiences is not limited to the sex of the partner but also the age at the first sexual experiences and the first sexual intercourse. Younger age at first sexual experiences is related to a higher risk of SVV in the form of sexual coercion.
} 


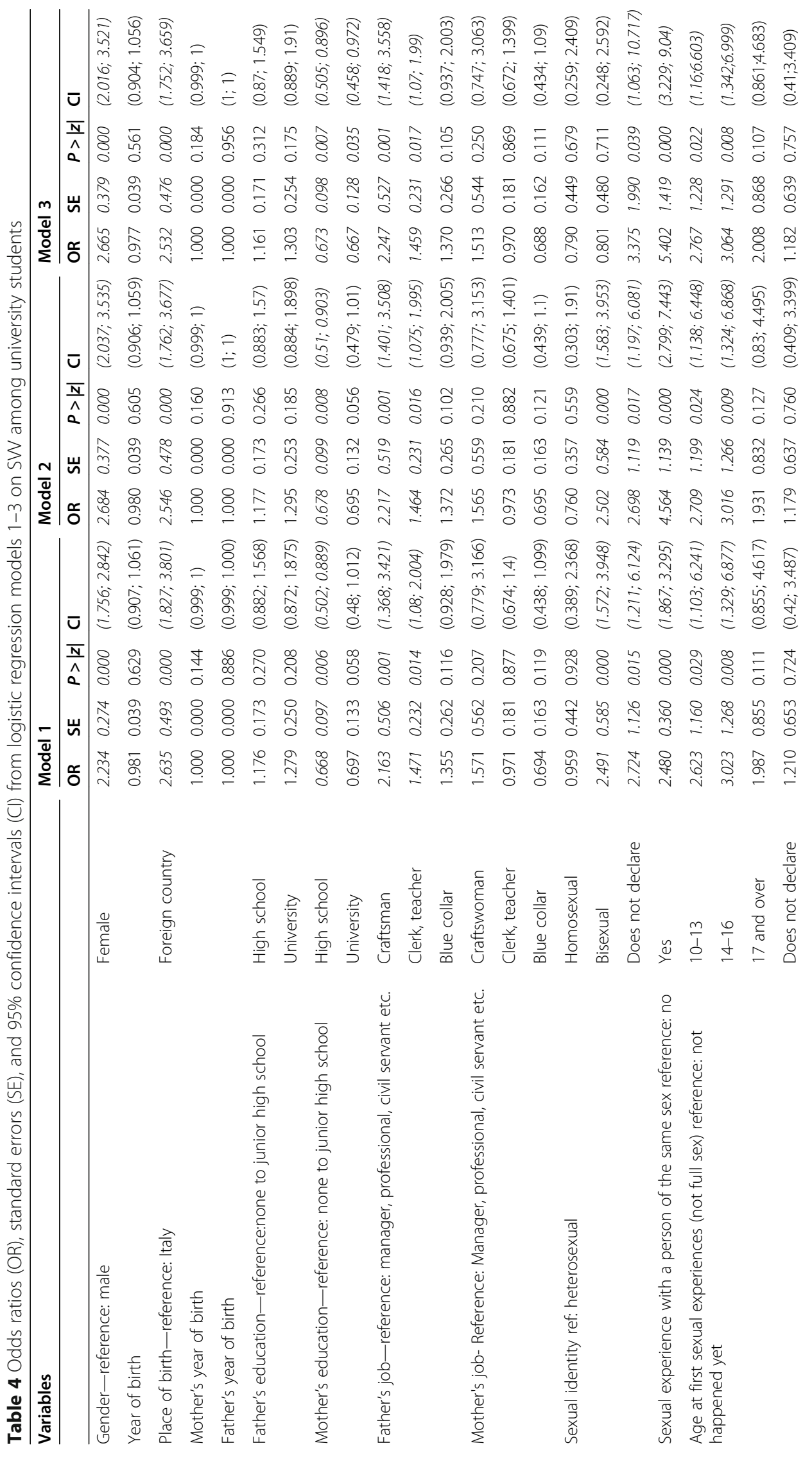




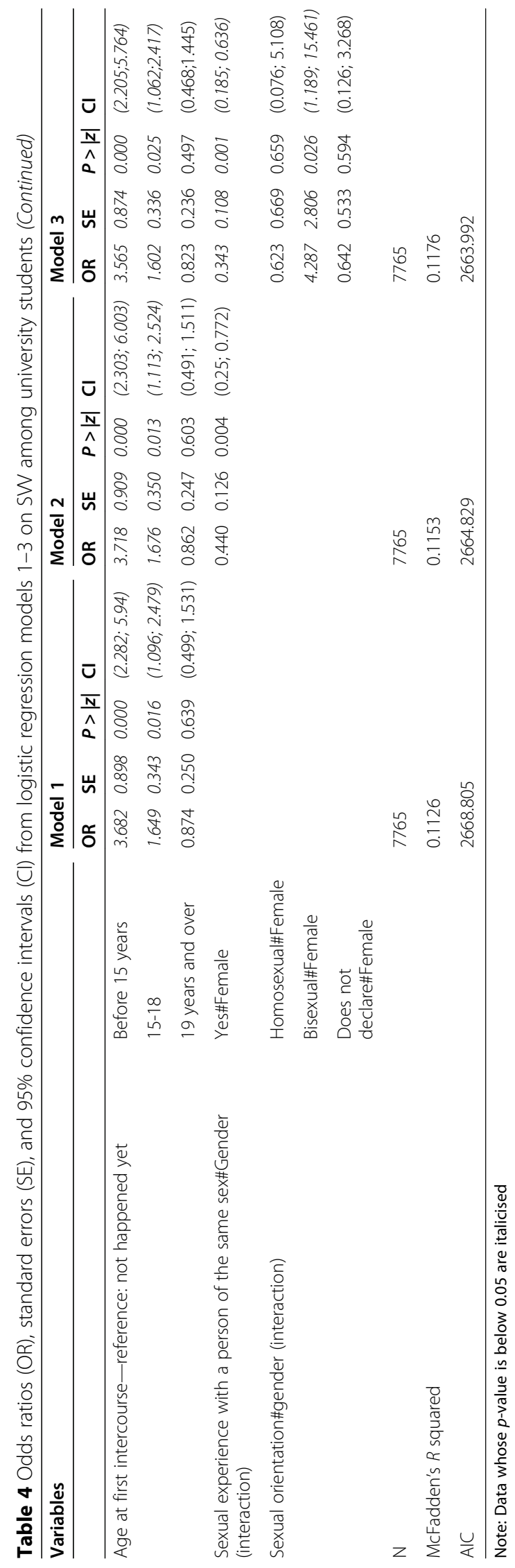


To better understand the implications of such results, we estimated the probability of experiencing SVV according to model 3 for different profiles. Fixed all other variables at their means, we can evaluate the effect of intersectionalities in the determination of SVV (RQ3). Among women, a very high probability of experiencing SVV is observed for bisexual women (Fig. 1): the risk is highest for foreign-born with previous same-sex sexual experience (0.419) and is still very high among foreign-born without previous same-sex sexual experience (0.280), natives with previous same-sex sexual experience (0.221), and natives without previous same-sex sexual experience (0.133). Among heterosexual women, the risk is lowest among natives with no same-sex sexual experiences (0.043) and highest among foreign-born with previous same-sex sexual experience (0.173). Homosexual women show some of the lowest levels of SVV estimated according to the model. The risk is also high among women who do not declare their sexual orientation, especially if they are foreign-born with previous same-sex sexual experience (0.312).

Among men (Fig. 2), the highest risk is estimated for heterosexual foreign-born with previous same-sex sexual experience (0.186). SVV is also high for foreign-born homosexual men with previous same-sex sexual experience (0.153). The lowest risk is estimated for bisexual and homosexual men without previous same-sex sexual experience (0.013) and heterosexual men (0.016) with no previous same-sex sexual experience.

Finally, the risk of SVV is unusually high for both female and male students who do not express their sexual orientation, especially if they are foreign-born and/or had previous same-sex sexual experiences.

\section{Conclusions}

According to our data, $4.7 \%$ of economics and statistics undergraduate students attending lessons in Italian public universities experienced SVV in the form of sexual coercion in their life (RQ1). Our data provide evidence of a higher risk of violence for female university students (6.7\%) compared with their male peers (2.8\%). Moreover, foreignborn students are also at higher risk of SVV (10.5\%). SELFY data also support previous evidence that bisexual students are at a higher risk of SVV (19.5\%) compared with students with other sexual orientation (Messinger, 2011; Whitfield et al., 2018). However, this effect is observed only for women.

Previous same-sex sexual experience is far more relevant than sexual orientation (RQ2), suggesting that violence mostly occurs in the framework of romantic relations rather than in the form of assaults driven by homophobia, as reported in similar surveys (Lebugle et al., 2018). Our results show that students who had had sexual encounters with same-sex partners have a higher incidence of sexual coercion.

The risk of SVV is unusually high for students who do not disclose their sexual orientation: their high risk of experiencing sexual coercion suggests that these may be de facto bisexual students because they experience similar risks patterns. This finding is particularly relevant in two ways. First, if we consider these students as "unsure" about their sexual orientation, we can hypothesise that they could be more open to different

\footnotetext{
${ }^{5}$ Control variables for parents' education and job position display the expected direction. The model shows a protective effect of the father's higher job position (a proxy for the socioeconomic status of the family) and a slight protective effect of mother's higher education.

${ }^{6}$ Control variables show that the role of sexual experiences is not limited to the sex of the partner but also the age at the first sexual experiences and the first sexual intercourse. Younger age at first sexual experiences is related to a higher risk of SVV in the form of sexual coercion.
} 


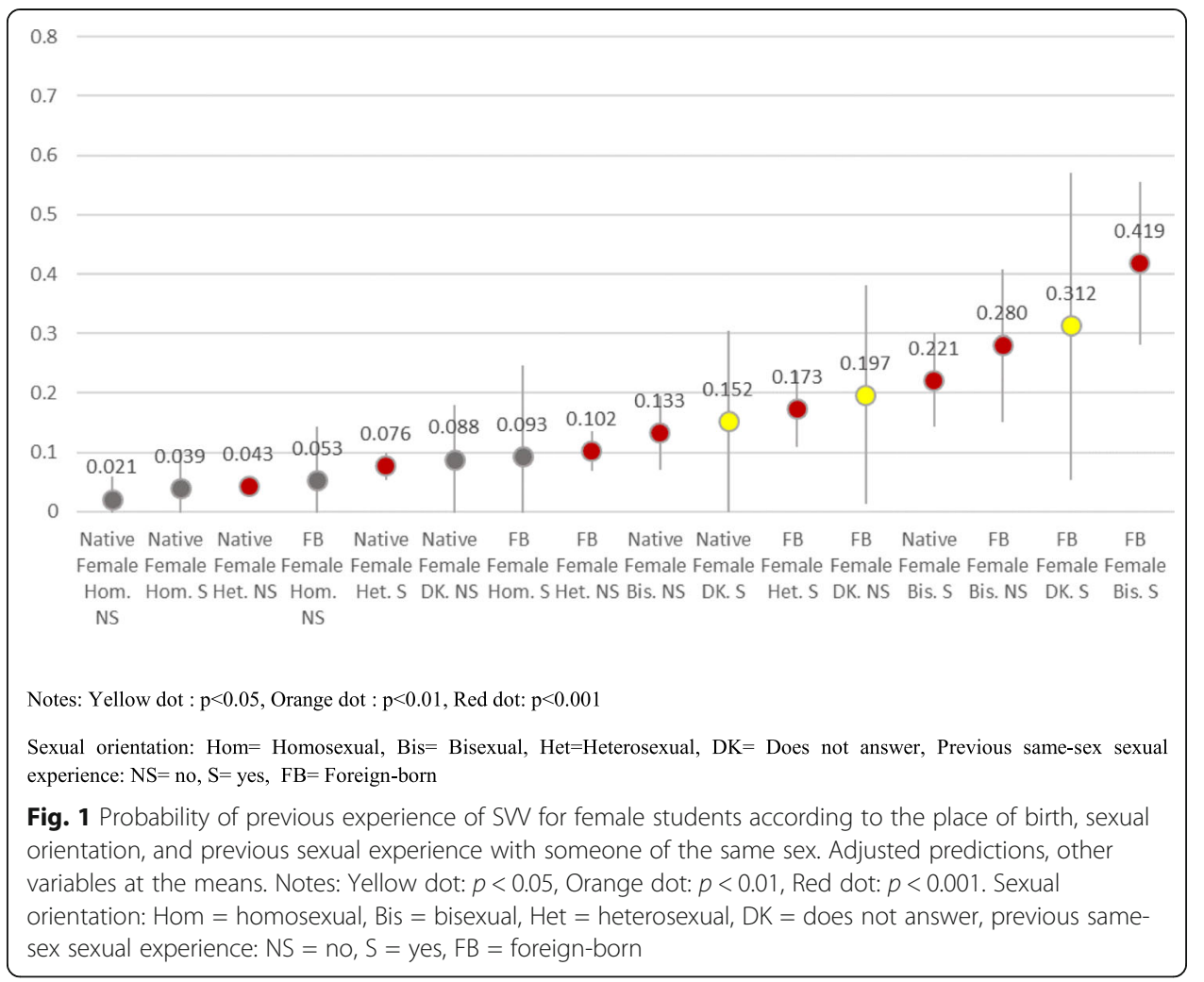

sexual experiences that, when occurred, could be perceived as forced due to limited awareness of their sexual desires. These students could also have more difficulties in disclosing their desires to others, including sexual partners, who could, therefore, propose sexual experiences that end up to be unwanted. Second, these findings support the need to design quantitative surveys and questionnaires that collect information on the self-declared sexual orientation along a continuum rather than in categorial fixed terms. Adopting such a fluid definition could help refine quantitative analyses by including respondents with a more fluid or still undefined sexual orientation.

Intersectionality emerges as a crucial aspect (RQ3): gender, same-sex sexual experience, and sexual orientation interact in shaping risk profiles. Bisexual women are considerably at a higher risk compared with bisexual men. At the same time, previous same-sex sexual experience results in a higher risk for men compared with women.

While showing a higher SVV among foreign-born students, as a limitation, we could not provide substantiated evidence for intersectionalities between the foreign background and gender, same-sex sexual experience, and sexual orientation. The number of foreign-born students in the sample was, in fact, not sufficiently large to assess the statistical significance of interactions with the other key dimensions of the analysis. Further research, including also Italian-born second generations, is needed to assess this point correctly and to overcome the limitations of this study that were previously discussed.

Young people's experiences of sexual abuse in the context of their relationships with peers have hardly been considered as a policy concern (Romito et al., 2013). Even if our contribution takes into consideration a very positively selected group of young people in terms of education and socioeconomic conditions, evidence still shows a need for 


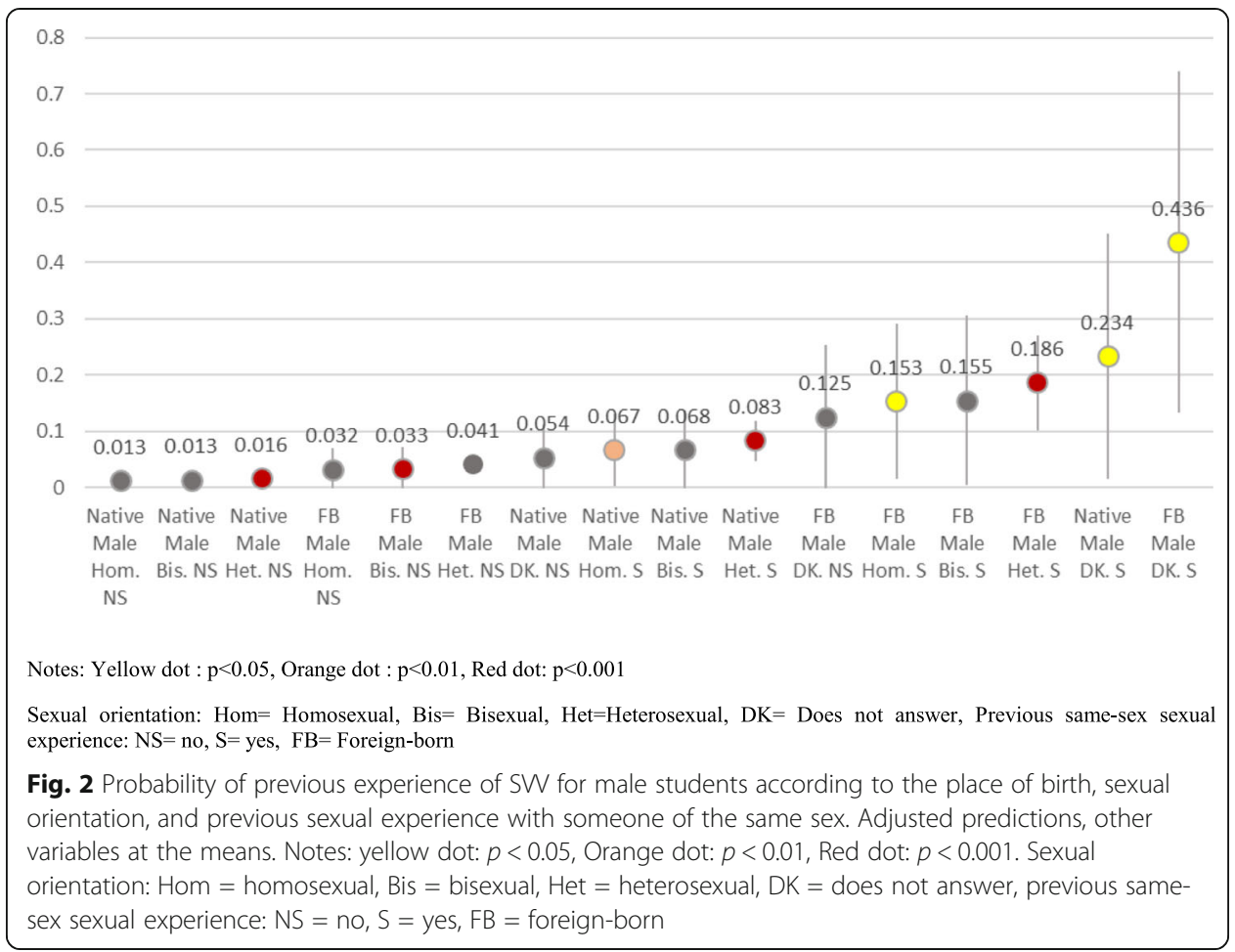

policies to raise awareness of sexual violence, but above all, the provision of support services.

The risks of sexual violence are far more significant among young women, who are not by chance the main target of specific actions even outside the boundaries of universities. However, empirical evidence showing a not insignificant prevalence of sexual violence suffered by men cannot be ignored. In this sense, university institutions should provide specialised care for men and women separately because the health and psychological consequences of SVV are differentiated by gender. Research has shown gendered differences in SVV consequences. Men are more likely to report externalising behaviours (e.g., substance use, aggressivity), while women are more likely to show internalising responses (e.g., depression) (Faravelli, Giugni, Salvatori, \& Ricca, 2004; Koss, 1993; Lebugle et al., 2018). Differentiation is also necessary by observing the condition of bisexual and homosexual young people. Actions targeting homophobia should have a clear focus on bisexuality, possibly acknowledging the lack of sexual scripts for sexual minorities and the risk of victimisation by both same-sex and different-sex partners in bisexual youngsters. Finally, foreign-born students are at higher risk of violence, even in the selected subpopulation of university students. Support for foreign-born (or second-generation) victims of sexual violence should take into account aspects like racism and discrimination on the one hand, and diversity management on the other.

Ultimately, the contribution underlines the need for university institutions to activate targeted strategies to mitigate the effects of violence suffered by students or in prevention actions according to specific profiles. An example of efforts in this sense is the European funded projects USV React that was recently carried out to provide training for university staff who may respond to disclosures of sexual violence (USV React, 2019). Nevertheless strong attention to SVV in the context of Italian university is still lacking. 


\section{Abbreviations}

AIC: Akaike information criterion; Cl: Confidence intervals; LGBT: Lesbian, gay, bisexual or transsexual; OR: Odds ratio; SE: Standard error; SELFY: Sexual and Emotional LiFe of Youths Survey; SW: Sexual violence victimisation; VIF: Variance inflation factor

\section{Acknowledgements}

An earlier version of the study was presented in the framework of the workshop on "Quantitative research on nonheterosexual populations" held in Milan on January 24, 2019, in Milan (Italy) at the Bocconi University.

\section{Authors' contributions}

LO contributed to the conception and design of the study, acquisition of the data, statistical analyses and interpretation of the data, drafting of the manuscript, and gave final approval for submission of the manuscript. PF contributed to the conception and design of the study, acquisition of the data, interpretation of the data, drafting of the manuscript, and gave final approval for submission of the manuscript.

\section{Funding}

Not applicable

\section{Availability of data and materials}

The data that support the findings of this study are available upon reasonable request from the SELFY study PIs and coordinator.

\section{Competing interests}

The authors declare that they have no competing interests.

\section{Author details}

${ }^{1}$ Alma Mater Studiorum, University of Bologna, Via delle Belle Arti 41, 40126 Bologna, Italy. ${ }^{2}$ University of MilanBicocca, Piazza dell'Ateneo nuovo 1, 20126 Milan, Italy.

Received: 10 July 2020 Accepted: 31 August 2020

Published online: 17 September 2020

\section{References}

Anthias, F. (2012). Transnational mobilities, migration research and intersectionality. Nordic Journal of Migration Research, 2(2), 102-108.

Arcilesbica (2011). Eva Contro Eva: I Convegno Sulla Violenza di Genere, (pp. 3-17). Roma: Arcilesbica Roma.

Arnett, J. J. (2000). Emerging adulthood: A theory of development from the late teens through the twenties. American Psychologist, 55, 469-480.

Association of American Universities (2020). Report on the AAU campus climate survey on sexual assault and misconduct Westat. Online resource https://www.aau.edu/sites/default/files/AAU-Files/Key-Issues/Campus-Safety/Revised\%2 OAggregate\%20report\%20\%20and\%20appendices\%201-7_(01-16-2020_FINAL).pdf.

Badenes-Ribera, L., Frias-Navarro, D., Bonilla-Campos, A., Pons-Salvador, G., \& Monterde-i-Bort, H. (2015). Intimate partner violence in self-identified lesbians: A meta-analysis of its prevalence. Sexuality Research \& Social Policy, 12, $47 \mathrm{https://doi}$ org/10.1007/s13178-014-0164-7.

Baldry, A. C., \& Winkel, F. W. (2004). Mental and physical health of italian youngsters directly and indirectly victimised at school and at home. International Journal of Forensic Mental Health Vol, 3, 77-91.

Beckstead, A. L. (2012). Can we change sexual orientation? Archives of Sexual Behavior, 41, 121-134.

Blondeel, K., de Vasconcelos, S., García-Moreno, C., Stephenson, R., Temmerman, M., \& Toskin, I. (2018). Violence motivated by perception of sexual orientation and gender identity : a systematic review. Bulletin of the World Health Organization, 96(1), 29-41.

Bugli, V., \& Conte, M. (2010). Giovani latinos e gruppi di strada nella metropoli milanese, in Queirolo Palmas [ed.], Atlantico latino. Gang giovanili e culture transnazionali. Rome: Carocci.

Buller, A. M., Devries, K. M., Howard, L. M., \& Bacchus, L. J. (2014). Associations between intimate partner violence and health among men who have sex with men: A systematic review and meta-analysis. PLoS Medicine, $11(3)$, e1 $001609 \mathrm{https} / / / \mathrm{doi}$ org/10.1371/journal.pmed.1001609.

Campbell, J. C. (2002). Health consequences of intimate partner violence. The Lancet, 359(9314), 1331-1336.

Choudhary, E., Coben, J. H., \& Bossarte, R. M. (2008). Gender and time differences in the associations between sexual violence victimization, health outcomes, and risk behaviors. American Journal of Men's Health, 2(3), 254-259.

Dalla Zuanna, G. P., Caltabiano, M., Minello, A., \& Vignoli, D. (2019). Catching up! The sexual opinions and behaviour of Italian students (2000-2017) University of Florence: Disia Working Paper 2019 /02.

Dardis, C. M., Dixon, K. J., Edwards, K. M., \& Turchik, J. A. (2015). An examination of the factors related to dating violence perpetration among young men and women and associated theoretical explanations: A review of the literature. Trauma, Violence \& Abuse, 16(2), 136-152.

Debauche, A., Lebugle, A., Brown, E., Lejbowicz, T., Mazuy, M., Charruault, A., ... Hamel, C. (2017). Présentation de l'enquête Virage et premiers résultats Sur les violences sexuelles. Documents de travail 229. Paris: Ined.

Decker, M. R., Raj, A., \& Silverman, J. G. (2007). Sexual violence against adolescent girls. Violence Against Women, 13(5), 498$513 \mathrm{https} / / /$ doi.org/10.1177/1077801207300654.

Depraetere, J., Vandeviver, C. \& Vander, B. T. (2018). Big boys don't cry: A critical interpretive synthesis of male sexual victimization. Trauma, Violence \& Abuse. https://doi.org/10.1177/1524838018816979.

Edwards, K. M., \& Sylaska, K. M. (2013). The perpetration of intimate partner violence among LGBTQ college youth: The role of minority stress. Journal of Youth and Adolescence, 42(11), 1721-1731. 
Edwards, K. M., Sylaska, K. M., Barry, J. E., Moynihan, M. M., Banyard, V. L., Cohn, E. S., ... Ward, S. K. (2015a). Physical dating violence, sexual violence, and unwanted pursuit victimisation: A comparison of incidence rates among sexual-minority and heterosexual college students. Journal of Interpersonal Violence, 30(4), 580-600.

Edwards, K. M., Sylaska, K. M., \& Neal, A. M. (2015b). Intimate partner violence among sexual minority populations: A critical review of the literature and agenda for future research. Psychology of Violence, 5(2), 112-121.

Elliott, D., Shui Ying Mok, D., \& Briere, J. (2004). Adult Sexual Assault: Prevalence, Symptomatology, and Sex Differences in the General Population. Journal of Traumatic Stress, 17(3), 203-211. https://doi.org/10.1023/B:JOTS.0000029263.11104.23.

Faravelli, C., Giugni, A., Salvatori, S., \& Ricca, V. (2004). Psychopathology after rape. American Journal of Psychiatry, 161(8), 14831485.

Fedina, L., Holmes, J. L., \& Backes, B. L. (2016). Campus sexual assault: A systematic review of prevalence research from 2000 to 2015. Trauma, Violence \& Abuse, 19(1), 76-93.

Fisher, B. S., Cullen, F. T., \& Turner, M. G. (2000). The sexual victimisation of college women, Research Report. Bureau of Justice Statistics (). Washington: US Department of Justice.

Ford, J., \& Soto-Marquez, J. G. (2016). Sexual assault victimization among straight, gay/lesbian, and bisexual college students. Violence and Gender, 3(2), 107-115.

Gagnon, J., \& Simon, W. (1973). Sexual conduct: The social sources of human sexuality. Aldine.

Gill, M., \& Tutty, L. M. (1998). Sexual identity issues for male survivors of childhood sexual abuse: A qualitative study. Journal of Child Sexual Abuse, 6(3), 31-47.

Gover, A. R., Kaukinen, C., \& Fox, K. A. (2008). The relationship between violence in the family of origin and dating violence among college students. Journal of Interpersonal Violence, 23(12), 1667-1693.

Griner, S. B., Vamos, C. A., Thompson, E. L., Logan, R., Vázquez-Otero, C., \& Daley, E. M. (2020). The Intersection of Gender Identity and Violence: Victimization Experienced by Transgender College Students. Journal of Interpersonal Violence, 35(23-24), 5704-5725 https://doi.org/10.1177/0886260517723743.

Harned, M. S. (2002). A multivariate analysis of risk markers for dating violence victimisation. Journal of Interpersonal Violence, 17(11), 1179-1197.

Henry N. (2019). Universities have made progress on responding to sexual assault, but there's more to be done. The Conversation February 10, 2019 http://theconversation.com/universities-have-made-progress-on-responding-to-sexual-assault-buttheres-more-to-be-done-111343 Accessed 11 Sept 2019

Hines, D. A. (2007). Predictors of sexual coercion against women and men: A multilevel, multinational study of university students. Archives of Sexual Behavior, 36(3), 403-422.

ISTAT (2015). La violenza contro le donne dentro e fuori la famiglia. Roma: ISTAT https://www.istat.it/it/files//2015/06/Niolenze_ contro_le_donne.pdf Accessed 6 Sept 2019.

ISTAT (2016). La violenza contro le donne. Online Resource. https://www.istat.it/it/archivio/194779

Koss, M., \& Oros, C. J. (1982). Sexual experiences survey: A research instrument investigating sexual aggression and victimisation. Journal of Consulting and Clinical Psychology, 50(3), 455-457 https://doi.org/10.1037/0022-006X.50.3.455.

Koss, M. P. (1993). Rape. Scope, impact, interventions, and public policy responses. American Psychologist, 48(10), 1062-1069.

Krahè, B., Scheinberger-Olwig, R., \& Bieneck, S. (2003). Men's reports of non-consensual sexual interactions with women: Prevalence and impact. Archives of Sexual Behavior, 32(2), 165-175.

Krebs, C. P., Lindquist, C., Warner, T., Fisher, B., \& Martin, S. (2007). The campus sexual assault (CSA) study: Final report Retrieved from the National Criminal Justice Reference Service: http://www.ncjrs.gov/pdffiles1/nij/grants/221153.pdf.

Kubicek, K. (2018). Setting an agenda to address intimate partner violence among young men who have sex with men: A conceptual model and review. Trauma, Violence \& Abuse, 19(4), 473-487.

Langenderfer-Magruder, L., Whitfield, D. L., Walls, N. E., Kattari, S. K., \& Ramos, D. (2016). Experiences of intimate partner violence and subsequent police reporting among lesbian, gay, bisexual, transgender, and queer adults in Colorado: Comparing rates of cisgender and transgender victimization. Journal of Interpersonal Violence, 31(5), 855-871 https://doi. org/10.1177/0886260514556767.

Larimer, M. E., Lydum, A. R., Anderson, B. K., \& Turner, A. P. (1999). Male and female recipients of unwanted sexual contact in a college student sample: Prevalence rates, alcohol use, and depression symptoms. Sex Roles, 40, 295-308.

Lebugle, A., Dupuis, J., et al. (2018). Les violences subies dans le cadre des études universitaires: Principaux résultats des enquêtes Violences et rapports de genre (Virage) réalisées auprès d'étudiants de 4 universités françaises. Documents de travail 245. Paris: Ined.

Lee, R. L., Yuen Loke, A., Hung, T. T., et al. (2018). A systematic review on identifying risk factors associated with early sexual debut and coerced sex among adolescents and young people in communities. Journal of Clinical Nursing, 27, 478-501.

Lehrer, J., Lehrer, E., \& Koss, M. (2012). Unwanted sexual experiences in adolescent and young adult men: Evidence from a survey of university students in Chile. Archives of Sexual Behavior, Advance online publication. https://doi.org/10.1007/ s10508-012-0004-X.

Lehrer, J. A., Lehrer, L. E., \& Koss, M. P. (2013). Sexual and dating violence among adolescents and young adults in Chile: A review of findings from a survey of university students. Culture, Health \& Sexuality, 15(1), 1-14 https://doi.org/10.1080/ 13691058.2012 .737934$.

List, K. (2013). Sexual violence and harassment against female students in Germany. Rivista di Criminologia. Vittimologia e Sicurezza, VII(2), 80-99.

Lloyd, C. (2007). The role of schools in promoting sexual and reproductive health among adolescents in developing countries. Poverty, Gender, and Youth Working Paper No 6. New York: Population Council.

Lockhart, L. L., White, B. W., Causby, V., \& Isaac, A. (1994). Letting out the secret. Journal of Interpersonal Violence, 9(4), 469-492 https://doi.org/10.1177/088626094009004003.

Lowry, R., Dunville, R., Robin, L., \& Kann, L. (2017). Early sexual debut and associated risk behaviors among sexual minority youth. American Journal of Preventive Medicine, 52(3), 379-384.

Marmocchi, P. (2012). Nuove generazioni. Genere, sessualità e rischio tra gli adolescenti di origine straniera. Milano: Franco Angeli.

Martin-Storey, A., Paquette, G., Bergeron, M., Dion, J., Daigneault, I., Hébert, M., \& Ricci, S. (2018). Sexual violence on campus: Differences across gender and sexual minority status. Journal of Adolescent Health, 62(6), 701-707. 
Maschile plurale (2020). Appelli e testi collettivi, la rete degli uomini https:/www.maschileplurale.it/category/appelli-e-testicollettivi/ last Access 5 May 2020.

Messinger, A. M. (2011). Invisible victims: same-sex IPV in the National Violence Against Women Survey. Journal of Interpersonal Violence, 26(11), 2228-2243 https://doi.org/10.1177/0886260510383023.

Mock, S. E., \& Eibach, R. P. (2012). Stability and change in sexual orientation identity over a 10-year period in adulthood. Archives of Sexual Behavior, 41(3), 641-648.

Ngo, Q. M., Veliz, P. T., Kusunoki, Y., Stein, S. F., \& Boyd, C. J. (2018). Adolescent sexual violence: Prevalence, adolescent risks, and violence characteristics. Preventive Medicine, 116, 68-74

O'brien, R. M. (2007). A caution regarding rules of thumb for variance inflation factors. Quality and Quantity, 41, 673-690 https://doi.org/10.1007/s11135-006-9018-6.

Offenhauer, P., \& Buchalter, A. (2011). Teen dating violence: A literature review and annotated bibliography. Washington DC: Federal Research Division, Library of Congress.

Pelullo, C. P., Di Giuseppe, G., \& Angelillo, I. F. (2013). Frequency of discrimination, harassment, and violence in lesbian, gay men, and bisexual in Italy. PLoS One, 8(8), e74446 https://doi.org/10.1371/journal.pone.0074446.

Peterson, Z. D., Voller, E. K., Polusny, M. A., \& Murdoch, M. (2011). Prevalence and consequences of adult sexual assault of men: Review of empirical findings and state of the literature. Clinical Psychology Review, 31(1), 1-24.

Porter, J., \& McQuiller, W. L. (2011). Intimate violence among underrepresented groups on a college campus. Journal of Interpersonal Violence, 26(16), 3210-3224.

Potter, S. J. (2016). Reducing sexual assault on campus: Lessons from the movement to prevent drunk driving. American Journal of Public Health, 106(5), 822-829.

Prino, L. E., Longobardi, C., \& Settanni, M. (2018). Young adult retrospective reports of adverse childhood experiences: Prevalence of physical, emotional, and sexual abuse in Italy. Archives of Sexual Behavior, 47, 1769-1778.

Reuter, T., Newcomb, M. E., Whitton, S. W., \& Mustanski, B. (2017). Intimate partner violence victimisation in LGBT young adults: Demographic differences and associations with health behaviors. Psychology of Violence, 7(1), 101-109 https://doi. org/10.1037/vio0000031.

Rollè, L., Giardina, G., Caldarera, A. M., Gerino, E., \& Brustia, P. (2018). When intimate partner violence meets same sex couples: A review of same sex intimate partner violence. Frontiers in Psychology, 9, 1506 https://doi.org/10.3389/fpsyg.2018.01506.

Romito, P., Beltramini, L., \& Escribà-Agüir, V. (2013). Intimate partner violence and mental health among italian adolescents: Gender similarities and differences. Violence Against Women, 19(1), 89-106.

Romito, P., \& Grassi, M. (2007). Does violence affect one gender more than the other? The mental health impact of violence among male and female university students. Social Science \& Medicine, 65(6), 1222-1234.

Sable, M. R., Danis, F., Mauzy, D. L., \& Gallagher, S. K. (2006). Barriers to reporting sexual assault for women and men: Perspectives of college students. Journal of American College Health, 55(3), 157-162.

SELFY (2019). Progetto SELFY sexual and emotional life of youths http://www.ricercaselfy.it/.

Silverman, J. G., Decker, M. R., \& Raj, A. (2007). Immigration-based disparities in adolescent girls' vulnerability to dating violence. Maternal and Child Health Journal, 11, 37-43 https://doi.org/10.1007/s10995-006-0130-y.

Sinozich, S., \& Langton, L. (2014). Rape and sexual assault victimization among college-age females, 1995-2013. US Department of Justice. Office of Justice Programs - Bureau of Justice Statistics https://www.bjs.gov/content/pub/pdf/rsavcaf9513.pdf Accessed 6 Sept 2019.

STIR-Safeguarding Teenage Intimate Relationships (2016). Executive summary and briefing paper 2 on violence in teenage intimate relationships https://cesie.org/media/Briefing-Paper-2_ENG.pdf.

USV React (2019). Training to respond to sexual violence at European universities: Final report of the USVreact project http:// usvreact.eu/it/about/

Vézina, J., \& Hérbert, M. (2007). Risk factors for victimisation in romantic relationships of young women. A review of empirical studies and implications for prevention. Trauma, Violence \& Abuse, 8(1), 33-66 https://doi.org/10.1177/1524838006297029.

Walters, M. L., Chen, J., \& Breiding, M. J. (2013). The National Intimate Partner and sexual violence survey (NISVS): 2010 findings on victimisation by sexual orientation. Atlanta: National Center for Injury Prevention and Control, Centers for Disease Control and Prevention.

Whitfield, D. L., Coulter, R. W. S., Langenderfer-Magruder, L., \& Jacobson, D. (2018). Journal of Interpersonal Violence. https://doi. org/10.1177/0886260518812071.

WHO - World Health Organization (2002). World report on violence and health. Geneva: WHO

WHO - World Health Organization (2012). Sexual violence Understanding and addressing violence against women. Geneva: WHO,

Wiersma-Mosley, J. D., \& Jozkowski, K. N. (2019). A brief report of sexual violence among universities with NCAA division I athletic programs. Behavioral sciences (Basel, Switzerland), 9(2), 17 https://doi.org/10.3390/bs9020017.

Williams, R. (2012). Using the margins command to estimate and interpret adjusted predictions and marginal effects. Stata Journal, 12(2), 308-331.

\section{Publisher's Note}

Springer Nature remains neutral with regard to jurisdictional claims in published maps and institutional affiliations. 